\title{
Electron beam characterization of a combined diode rf electron gun
}

\author{
R. Ganter, B. Beutner, S. Binder, H. H. Braun, T. Garvey, C. Gough, C. Hauri, R. Ischebeck, S. Ivkovic, F. Le Pimpec, \\ K. Li, M. L. Paraliev, M. Pedrozzi, T. Schietinger, B. Steffen, A. Trisorio, and A. Wrulich \\ Paul Scherrer Institute, 5232 Villigen PSI, Switzerland
}

(Received 1 April 2010; published 20 September 2010)

\begin{abstract}
Experimental and simulation results of an electron gun test facility, based on pulsed diode acceleration followed by a two-cell rf cavity at $1.5 \mathrm{GHz}$, are presented here. The main features of this diode-rf combination are: a high peak gradient in the diode (up to $100 \mathrm{MV} / \mathrm{m}$ ) obtained without breakdown conditioning, a cathode shape providing an electrostatic focusing, and an in-vacuum pulsed solenoid to focus the electron beam between the diode and the rf cavity. Although the test stand was initially developed for testing field emitter arrays cathodes, it became also interesting to explore the limits of this electron gun with metallic photocathodes illuminated by laser pulses. The ultimate goal of this test facility is to fulfill the requirements of the SwissFEL project of Paul Scherrer Institute [B.D. Patterson et al., New J. Phys. 12, 035012 (2010)]; a projected normalized emittance below $0.4 \mu \mathrm{m}$ for a charge of $200 \mathrm{pC}$ and a bunch length of less than $10 \mathrm{ps}$ (rms). A normalized projected emittance of $0.23 \mu \mathrm{m}$ with $13 \mathrm{pC}$ has been measured at $5 \mathrm{MeV}$ using a Gaussian laser longitudinal intensity distribution on the photocathode. Good agreements with simulations have been obtained for different electron bunch charge and diode geometries. Emittance measurements at a bunch charge below $1 \mathrm{pC}$ were performed for different laser spot sizes in agreement with intrinsic emittance theory [e.g. $0.54 \mu \mathrm{m} / \mathrm{mm}$ of laser spot size (rms) for $\mathrm{Cu}$ at $274 \mathrm{~nm}$ ]. Finally, a projected emittance of $1.25+/-0.2 \mu \mathrm{m}$ was measured with $200 \mathrm{pC}$ and $100 \mathrm{MV} / \mathrm{m}$ diode gradient.
\end{abstract}

DOI: 10.1103/PhysRevSTAB.13.093502

PACS numbers: 29.25.Bx, 41.60.Cr, 85.60.Ha, 52.59.Sa

\section{INTRODUCTION}

In the context of the SwissFEL project [1-3], an electron gun test stand has been developed and built to generate, transport, and characterize low emittance electron beams. This diode-rf gun was initially [4] designed in order to use field emitter arrays (FEA) [5,6] as an electron source for an FEL. While the development of FEA is still going on at Paul Scherrer Institute (PSI), the diode-rf gun has been characterized with a metallic photocathode and a laser as a trigger source. This paper summarizes the performance of this diode-rf gun when used with metallic photocathodes illuminated by vacuum ultraviolet laser pulses.

In an electron gun the beam emittance results from three main contributions: (1) the intrinsic emittance due to the electron emission process, (2) the contribution due to space charge forces, and (3) the contribution due to external fields [radio frequency (rf); electrostatic, ...]. To reduce the intrinsic emittance, one can either change the laser wavelength to match the work function of the emitting material or reduce the diameter of the emitting area. The latter results in stronger space charge forces which can again increase the emittance. Space charge emittance degradation can be reduced by using a stronger accelerating gradient. The gradient is limited however by vacuum breakdown. Finally, nonlinear external fields, such as rf field curvature in $\mathrm{rf}$ photoinjector cavities or the nonlinear radial fields near the anode iris of dc guns, also lead to emittance growth. As in other diode-rf gun combinations [7-11], the goal is to reduce all three of these contributions.
In our dc gun the electric field gradient is much lower than in other pulsed dc-rf guns $(1 \mathrm{GV} / \mathrm{m})[9,10,12]$ and comparable to $\mathrm{rf}$ photoinjector accelerating gradient $(100 \mathrm{MV} / \mathrm{m})[13,14]$. In our design $100 \mathrm{MV} / \mathrm{m}-500 \mathrm{kV}$ is reached in the diode without conditioning and no dark current is detected downstream of the anode. In addition, the cathode geometry is shaped such that it produces nonlinear focusing forces which compensate the nonlinear defocusing forces due to space charge and radial field at anode iris. Another feature of the presented diode-rf gun design, is the presence of an in-vacuum pulsed solenoid which has been installed between the diode and the rf cavity in order to match the beam to the rf acceleration and preserve emittance. Finally, thanks to a wavelength tunable laser, we have demonstrated the possibility of decreasing the intrinsic emittance [15].

A detailed description of the test facility is presented in Sec. II and simulations of the beam dynamics in the gun are presented in Sec. III. Experimental results and discussion are presented in Sec. IV. The ultimate goal of this test stand is to provide electron bunches of 10 and $200 \mathrm{pC}$ charge at $5 \mathrm{MeV}$ with projected normalized emittances below 0.25 and $0.4 \mu \mathrm{m}$, respectively, in order to fulfill the SwissFEL parameter requirements [3].

\section{DIODE/RF GUN TEST STAND DESCRIPTION}

\section{A. The pulsed diode acceleration section}

The main emittance growth takes place in the diode section of the gun during the initial acceleration due to 
nonlinear space charge forces and nonlinear defocusing forces near the inner surface of the anode iris. High electric gradient and electrostatic transverse focusing are required in order to compensate partially the space charge effects and the nonlinear defocusing field around the anode iris. The high voltage applied across the diode is pulsed $(250 \mathrm{~ns}$ FWHM) with a $10 \mathrm{~Hz}$ repetition rate in order to reduce the probability of breakdown [16]. The cathode geometry can be exchanged between a simple elliptical shape used for electrical gradient tests and a so-called "hollow cathode" geometry (see Figs. 1 and 2) to provide electrostatic focusing. The design of the hollow cathode allows the testing of $14 \mathrm{~mm}$ diameter disk inserts [field emitter arrays (FEA) or different photocathode materials]. The disk edges are covered by the hollow cathode. In addition, the lips holding the cathode insert deform the electric field lines and provide electrostatic transverse focus to the electron beam (see Fig. 2 right). The on-axis electric field on the insert surface is about half of the field present on the lips of the cathode surface.

The maximum electric field between the electrodes is limited by vacuum breakdown, which can damage the photoemitting surface. In the case of a coated electrode, one breakdown is sufficient to destroy the coating such that not even a small gradient ( $>20 \mathrm{MV} / \mathrm{m}$ ) can be sustained.

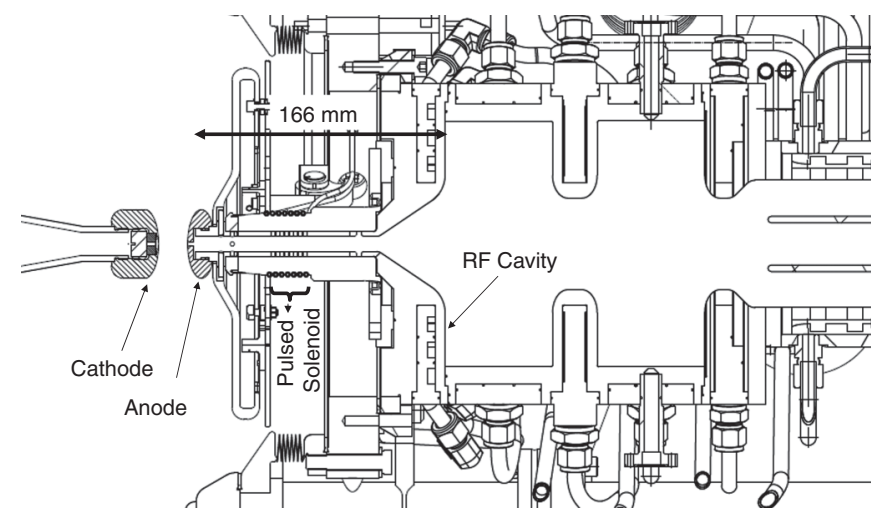

FIG. 1. Section through the diode/rf gun combination.
In consequence, our electrodes are not conditioned and no dark current is observed after the anode iris (down to the detection limit corresponding to $1 \mathrm{pC}$ in $250 \mathrm{~ns}$ ). An empirical study of electric field strength for different materials and surface finish has been performed and is partially summarized in Table I. Except for Mo and DLC, the gradient values are taken from [17]. For this study a simplified elliptically shaped cathode and anode were used. The high gradient test procedure consists of three steps: (1) at a gap of $1 \mathrm{~mm}$, the gradient is increased to $50 \mathrm{MV} / \mathrm{m}$, (2) the gap is opened up to $7 \mathrm{~mm}$ while the gradient is kept constant and the voltage is increased from $50 \mathrm{kV}$ to $350 \mathrm{kV}$, and (3) gap is reduced at a constant voltage of $350 \mathrm{kV}$ until it breaks down.

Each material or coating presented in Table I was tested with at least five different pairs of electrodes to check the reproducibility. The metallic surfaces were hand polished with diamond paste and spray cleaned with dry ice $\left(\mathrm{CO}_{2}\right.$ snow) before installation $[17,18]$. The Mo coating was deposited in house by sputtering and the diamond like carbon (DLC) coating was deposited by Bekaert SA [19]. DLC gave very good results: more than eight DLC electrode pairs were able to sustain a surface electric field of at least $150 \mathrm{MV} / \mathrm{m}$ (more details can be found in [6]). Consequently, DLC became our material of choice to coat the hollow cathode geometry presented in Fig. 2. The emitting area (the inserted disk), however, is not coated and sees a surface field of about the half of the peak diode accelerating field.

Simulations of the hollow cathode geometry using the code POISSON [20] (Fig. 2, right) show that the electric field on the axis of the insert surface is about half of the maximum surface field present on the DLC coated holding lips and does not change by more than $10 \%$ for different anode-cathode gaps $(1.5$ to $6 \mathrm{~mm})$. Since this geometry provides transverse focusing, the positioning and orientation of the cathode (red arrows on Fig. 2) allows the control of the beam trajectory and shape before it enters the $\mathrm{rf}$ cavity for further acceleration. The cathode longitudinal, transverse, and tilt positions are remotely controlled by

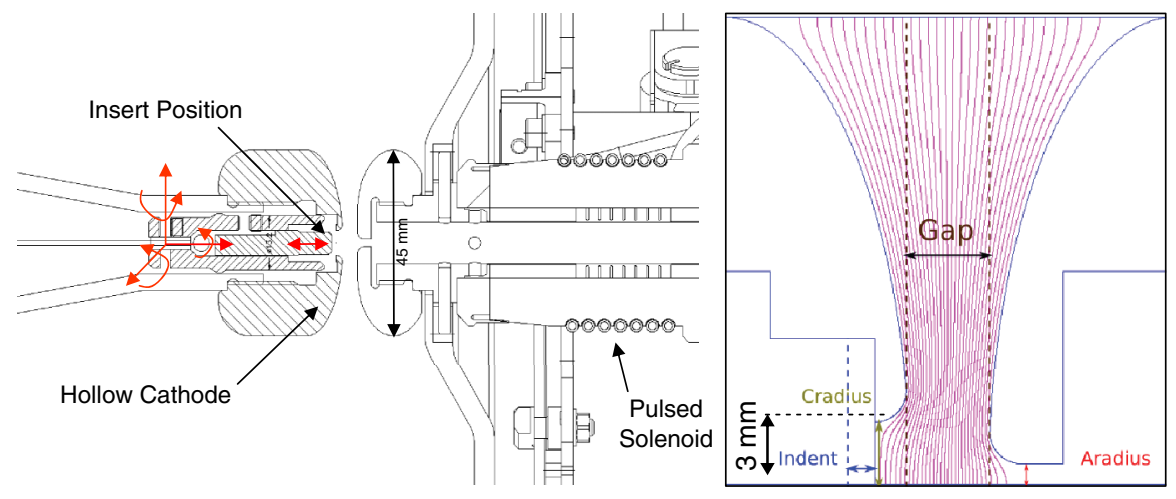

FIG. 2. Left: Cross section of the diode assembly with the hollow cathode geometry. Right: Zoom on the hollow cathode geometry showing the equipotential lines. 
TABLE I. Range of maximum electric field sustained by different electrodes in the diode (without conditioning and without laser illumination) for gaps ranging between 1.5 and $6 \mathrm{~mm}$.

\begin{tabular}{lcc}
\hline \hline Electrodes material (anode and cathode) & Maximum electric gradient before breakdown & Reference \\
\hline Stainless steel & 70 to $140 \mathrm{MV} / \mathrm{m}$ & {$[17]$} \\
Aluminum & 46 to $60 \mathrm{MV} / \mathrm{m}$ & {$[17]$} \\
Niobium & 60 to $83 \mathrm{MV} / \mathrm{m}$ & {$[17]$} \\
Copper & 74 to $83 \mathrm{MV} / \mathrm{m}$ & {$[17]$} \\
TiVAl alloy & 70 to $130 \mathrm{MV} / \mathrm{m}$ & {$[17]$} \\
Molybdenum coating & 140 to $210 \mathrm{MV} / \mathrm{m}$ & {$[6]$} \\
Diamond like carbon coating (DLC) & 150 to $320 \mathrm{MV} / \mathrm{m}$ & {$[6]$} \\
\hline \hline
\end{tabular}

stepper motors (rotation over a few mrad around the cathode axis is also possible but not used here). The insert can also move longitudinally independently of the cathode holder.

\section{B. The rf cavity and the diagnostic line}

Because of mechanical constraint, the anode is separated from the rf cavity entrance plane by a drift distance of $d_{\text {anode-rf }}=166 \mathrm{~mm}$. To prevent an expansion of the beam during this drift and to match the beam size to the $\mathrm{rf}$ accelerating cavity [21], a $25 \mathrm{~mm}$ long pulsed solenoid is located $51 \mathrm{~mm}$ downstream of the anode iris. The pulsed solenoid (Fig. 2, left) consists of a coil concentric with an inner ring of $1 \mathrm{~cm}$ diameter [22]. Current pulses of up to $2 \mathrm{kA}$ and $100 \mu$ s duration are applied to the outer coil inducing a current pulse in the inner ring, leading to a maximum magnetic field of $B_{\mathrm{PSL}}=320 \mathrm{mT}$ on axis. This compact pulsed focusing technology was chosen in order to fit the available space between the diode and the $\mathrm{rf}$ cavity. No residual magnetic field is present on the cathode surface due to the eddy currents in the materials surrounding the pulsed solenoid. The two-cell rf cavity [23] (Fig. 1) has a frequency of $1.5 \mathrm{GHz}$ and is fed through a $50 \mathrm{Ohm}$ coaxial coupler with an rf forward power $P_{\mathrm{rf}}$ of up to $5 \mathrm{MW}$ with $5 \mu$ s long pulses, yielding to a maximum accelerating gradient of $45 \mathrm{MV} / \mathrm{m}$. The maximum accelerating gradient used in the cavity was $42 \mathrm{MV} / \mathrm{m}$. A standard $1.5 \mathrm{GHz}$ power splitter was designed to equally distribute the rf power from the klystron between the two waveguides leading to the coaxial coupler. The repetition rate of the laser, pulser, and rf is presently limited to $10 \mathrm{~Hz}$. Figure 3 shows the layout of the full diagnostic beam line which includes seven fluorescent screens (YAG:Ce crystals), placed along the beam axis for measurements of the transverse beam profile. The two solenoid magnets downstream of the rf cavity focus the beam in the emittance monitor. They can provide a maximum field of $B_{\mathrm{DSL}}=250 \mathrm{mT}$ and are $0.2 \mathrm{~m}$ long. Eight pairs of vertical and horizontal corrector magnets $(0.5 \mathrm{mT}$ maximum field; $1 \mathrm{~cm}$ length) are distributed along the axis downstream of the rf cavity. The projected emittance is measured with a pepper-pot technique [24] at different locations along the emittance monitor [25] and cross correlated with a solenoid scan technique [15] for very low charge (1 pC or less) (Fig. 3). A spectrometer setup [26], made of a $230 \mathrm{~mm}$ long dipole magnet and two screens, follows the emittance monitor. The two screens are equidistant from the dipole center, one screen on the gun axis (reference screen to measure beam size) and one screen on the dispersive arm (to measure momentum and momentum spread). The dispersive arm makes a $30^{\circ}$ angle with the gun axis. The nominal bending magnetic field required for a $4 \mathrm{MeV}$ beam is $B_{\text {dipole }}=34 \mathrm{mT}$. A quadrupole doublet in front of the dipole provides horizontal magnetic focusing and limits the beam size vertically on the spectrometer arm screen. Various electron bunch charge diagnostics [wall current monitor (WCM), integrating current transformer (ICT), and Faraday cups] are distributed along the beam line (Fig. 3).

\section{The laser system}

Two independent laser systems were used for the results presented here: a frequency quadrupled Nd:YLF laser with regenerative amplifier providing a fixed wavelength of $262 \mathrm{~nm}$ and a wavelength tunable Ti:sapphire based system which provides laser pulses with wavelengths ranging from

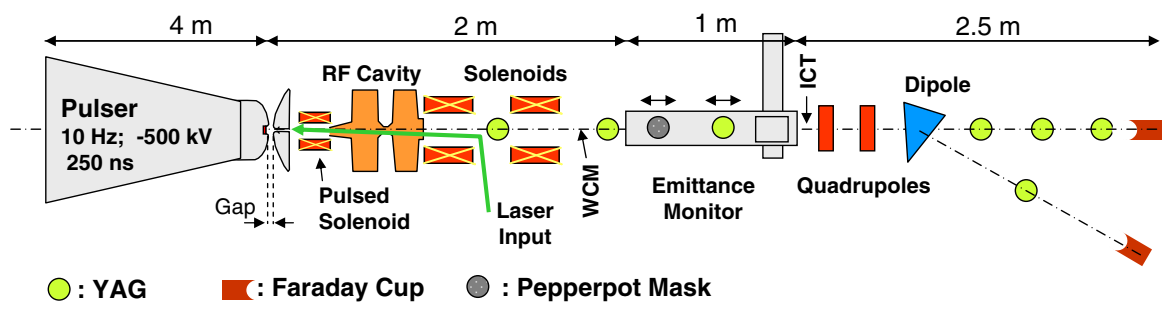

FIG. 3. Schematic of the diode-rf gun and diagnostic beam line. 
262 to $282 \mathrm{~nm}$. Details of those systems can be found elsewhere [15,27]. In order to obtain a uniform transverse intensity profile, both lasers are first expanded and sent through a mask aperture which selects a small fraction of the Gaussian transverse profile. The diameter $D_{\text {laser }}$ of the laser spot on the cathode can be varied by changing the aperture mask diameter $\left(0.5 \mathrm{~mm}<D_{\text {laser }}<1.8 \mathrm{~mm}\right)$. Both lasers have a Gaussian longitudinal profile. The duration for the Nd:YLF system is $\sigma_{t, \text { laser }}=4.2 \mathrm{ps}$. The pulse length of the other laser system is variable The accelerating diode voltage pulse length of $250 \mathrm{~ns}$ is significantly longer than the laser pulse duration and appears as a DC acceleration.

\section{The pepper-pot analysis tool}

The emittance monitor assembly consists of independently movable pepper-pot and YAG:Ce screen from $z=$ $2.1 \mathrm{~m}$ to $2.6 \mathrm{~m}$. The pepper-pot mask has a diameter of $5 \mathrm{~mm}$, with a hole spacing of 250 and $50 \mu \mathrm{m}$ hole diameter. The tungsten mask thickness is $0.5 \mathrm{~mm}$ and the distance to the screen can be varied from 0 up to $0.5 \mathrm{~m}$. More details on the emittance monitor system can be found in [25]. The vertical (horizontal) alignment of the pepper-pot mask is done with a He:Ne alignment laser and by rotation of the camera. Pitch and yaw are not corrected so that the projected hole size might be smaller than the real hole size. The final emittance resolution of the device taking into account the camera pixel size has been measured with a laser light to be $0.03 \mu \mathrm{m}$.

For the evaluation of pepper-pot images we follow Ref. [28]. Using their notation we describe the pepper pot as a sequence of pinholes with spacing $w$ significantly larger than the hole diameter $d$, separated by a distance $L$ from the detection screen. In one projection (horizontal or vertical), the transmitted beam is split into $N$ beamlets, numbered from $m=0, \ldots, N-1$.

Applying a statistical approach the rms beam emittance and the rms Twiss parameters are constructed from the beam's second-order moments:

$$
\begin{gathered}
\varepsilon_{x}=\sqrt{\left\langle x^{2}\right\rangle\left\langle x^{\prime 2}\right\rangle-\left\langle x x^{\prime}\right\rangle^{2}} \\
\beta_{x}=\frac{\left\langle x^{2}\right\rangle}{\varepsilon_{x}} \\
\alpha_{x}=-\frac{\left\langle x x^{\prime}\right\rangle}{\varepsilon_{x}} \\
\gamma_{x}=\frac{\left\langle x^{\prime 2}\right\rangle}{\varepsilon_{x}}=\frac{1+\alpha_{x}^{2}}{\beta_{x}}
\end{gathered}
$$

and similarly for the rms beam size,

$$
\sigma_{x}=\sqrt{\left\langle x^{2}\right\rangle}=\sqrt{\beta_{x} \varepsilon_{x}} .
$$

The second-order moments can be extracted from the main beamlet properties: the centroid positions $x_{m}$, the centroid trajectory slopes $x_{m}^{\prime}$, the intensities $I_{m}$, and the rms divergence spreads $\sigma_{m}^{\prime}$ :

$$
\begin{gathered}
\left\langle x^{2}\right\rangle=\frac{\sum_{m} I_{m} x_{m}{ }^{2}}{I_{\mathrm{tot}}} \\
\left\langle x^{\prime 2}\right\rangle=\frac{\sum_{m} I_{m}\left(x_{m}^{\prime}{ }^{2}+\sigma_{m}{ }^{\prime 2}\right)}{I_{\mathrm{tot}}} \\
\left\langle x x^{\prime}\right\rangle=\frac{\sum_{m} I_{m} x_{m} x_{m}^{\prime}}{I_{\mathrm{tot}}}
\end{gathered}
$$

with $I_{\text {tot }}=\sum I_{m}$ and all the summations running over the full set of beamlets, from $m=0$ to $m=N-1$. The beamlet intensity $I_{m}$ is obtained by summing up the detected intensities for pixel column (or line) $j$ within a range associated with beamlet $m: I_{m}=\sum_{j} I_{j}$. Figure 4 represents actually the column intensities $I j$ versus the pixel column $j$. Both $x_{m}$ and $x_{m}^{\prime}$ are centered, i.e.,

$$
\begin{gathered}
x_{m}=x_{m, 0}-\sum_{n} I_{n} x_{n, 0} / I_{\mathrm{tot}} \\
x_{m}^{\prime}=x_{m, 0}^{\prime}-\sum_{n} I_{n} x_{n, 0}^{\prime} / I_{\mathrm{tot}} .
\end{gathered}
$$

The original beamlet positions are simply given by the center to center hole spacing $w$ (with arbitrary but irrelevant offset),

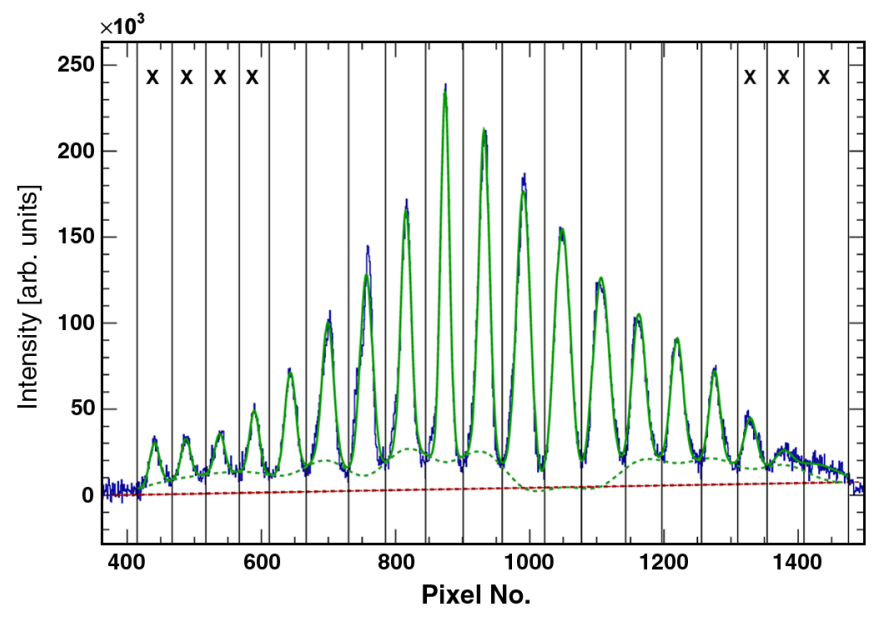

FIG. 4. Histogram of the horizontal projections ( 1 pixel $=$ $6.15 \mu \mathrm{m}$ ) of all pepper-pot beamlets (blue line), only $90 \%$ of the core beam is taken into account for emittance evaluation and rejected beamlets are indicated with a cross. The green line corresponds to the multi-Gaussian fits assuming a local background (dashed green line) to avoid beamlet overlap effects. The red dashed line corresponds to the background without beam. $\left(\gamma \mathrm{mc}^{2}=6.35 \mathrm{MeV} ; 200 \mathrm{pC} ; V_{\text {pulser }}=510 \mathrm{kV} ; g=6 \mathrm{~mm} ; z=\right.$ $2.3 \mathrm{~m} ; \sigma_{t, \text { laser }}=3 \mathrm{ps}$, Gaussian time profile; $D_{\text {laser }}=0.9 \mathrm{~mm}$; $\left.\varepsilon_{n X}=1.3 \pm 0.2 \mu \mathrm{m}\right)$. 


$$
x_{m, 0}=m w \text {. }
$$

For the determination of the beamlet centroid positions and widths, we refrain from using a simple statistical method (mean and rms) since even small levels of background can have large effects on the result. Instead we apply a least-squares fit to the beamlet profile. The fit function is chosen to be the sum of $N$ Gaussians and, if necessary, an appropriate background function. Supplied with reasonable starting values derived from the statistical means and rms values, the fit converges quickly and returns the beamlet centroids $\mu_{m}^{\mathrm{fit}}$ and widths $\sigma_{m}^{\mathrm{fit}}$ in pixels. These values are then converted to the trajectory slopes of the beamlet centroids,

$$
x_{m, 0}^{\prime}=\frac{\mu_{m}^{\mathrm{fit}} p-x_{m, o}}{L}
$$

and the divergence spreads $\sigma_{m, 0}^{\prime}$ (the hole diameter $d$ is subtracted quadratically),

$$
\sigma_{m, 0}^{\prime}=\frac{\sqrt{\left(\sigma_{m}^{\mathrm{fit}} p\right)^{2}-\left(\frac{d}{4}\right)^{2}}}{L},
$$

where $p$ denotes the spatial extension of an image column (pixel size). Neglecting the hole size leads usually to an emittance increase of about $10 \%$. To avoid possible optical or geometrical distortions from multirow (or multicolumn) projections, we use the projection of one to a few beamlet rows (or columns) near the center of the beam for emittance analysis. Given the rms definition of beam emittance, small beamlets at the beam periphery can have a large effect on the emittance while contributing only little to the total charge. To avoid the inevitable associated uncertainties in the determination of the emittance of the total beam, we restrict the analysis to the central beamlets contributing $90 \%$ of the total charge.

A user-friendly application XANAROOT [29] based on the method described above was used for all emittance measurements presented here. Figure 4 illustrates a typical histogram obtained for a $200 \mathrm{pC}$ beam. Rejected beamlets which are outside the $90 \%$ of the core beam are marked with a cross. With $90 \%$ charge the resulting normalized emittance is $1.3 \mu \mathrm{m}$ and becomes $1.7 \mu \mathrm{m}$ when taking all visible beamlets (100\% charge) in Fig. 4. The green curve illustrates the profile fit used to estimate the beamlet width. The estimation of the beam boundary (to define 100\% charge) is the main source of error. In order to give a realistic error bar on emittance, we used the difference between the $100 \%$ charge emittance and the $90 \%$ one. This difference is then defined as the total error bar size in all presented emittance results $\left(\Delta \varepsilon=\varepsilon_{100 \%}-\varepsilon_{90 \%}\right)$.

\section{BEAM DYNAMICS SIMULATIONS OF THE DIODE-RF GUN}

ASTRA [30] simulations were performed in order to describe the emittance evolution along the machine axis (Fig. 5). The diode part with the hollow cathode geometry was first simulated with POISSON [20] in order to get the appropriate field map (see Fig. 2, right inset). Figure 5 (top) represents the evolution of the beam size and emittance over the $4 \mathrm{~m}$ long test stand. The zero position $(z=0)$ of the machine is taken at the anode surface. The bottom graph of Fig. 5 is a zoom of the diode to rf section (120 mm long). In the diode section the emittance increases very rapidly after a few $\mathrm{mm}$ from its initial intrinsic

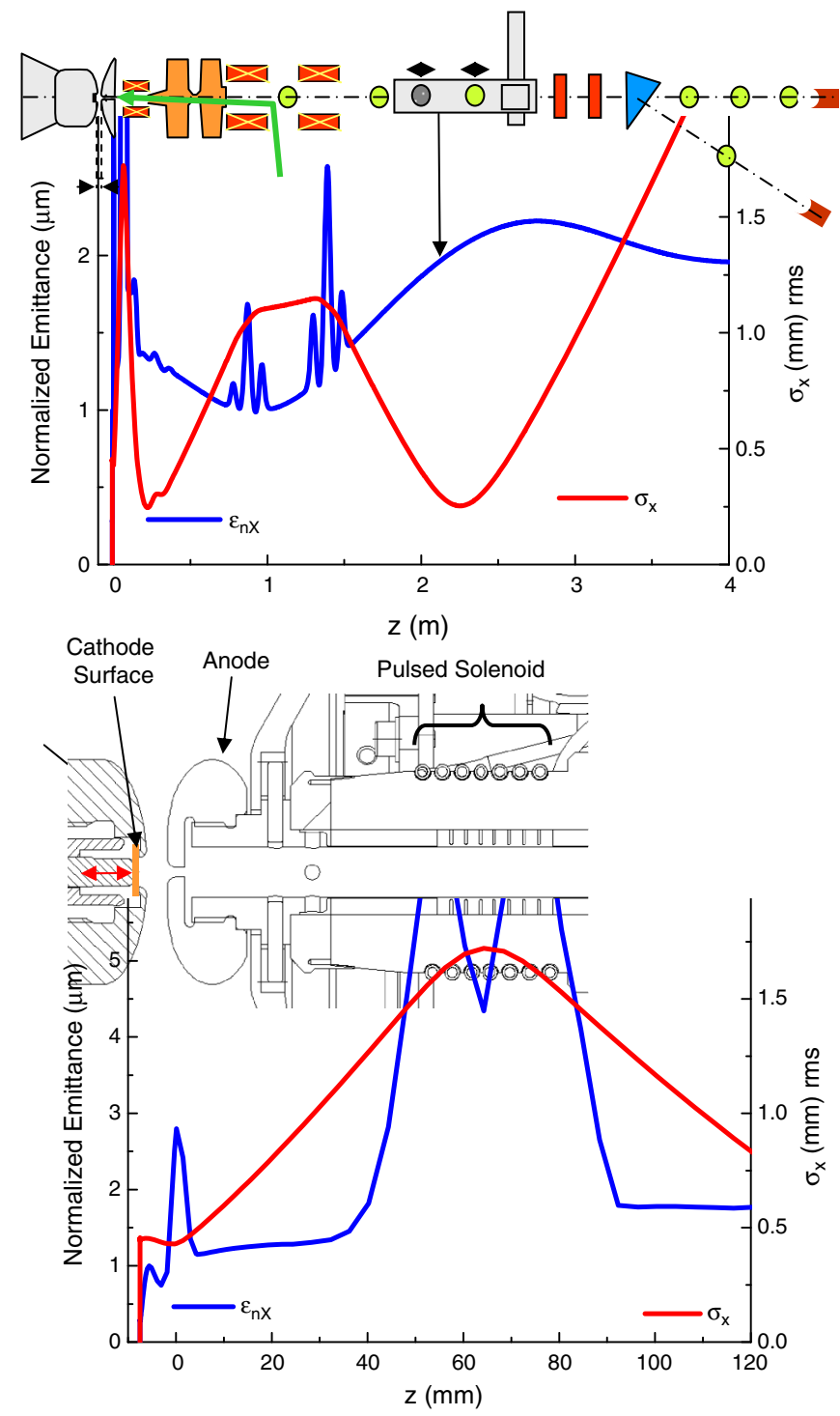

FIG. 5. ASTRA simulation of projected normalized emittance (90\% charge) and transverse beam size (rms) versus $z$, over the first $120 \mathrm{~mm}$ (bottom graph) and over the full diagnostic line (top graph) $\left(V_{\text {pulser }}=300 \mathrm{kV}\right.$; gap $=6 \mathrm{~mm}$; Gaussian time profile $\left.\sigma_{t, \text { laser }}=4.2 \mathrm{ps} ; D_{\text {laser }}=1.4 \mathrm{~mm} ; \gamma \mathrm{mc}^{2}=5.41 \mathrm{MeV} ; 200 \mathrm{pC}\right)$. 
value $(0.2 \mu \mathrm{m}$ at $z=-6 \mathrm{~mm})$ to $\sim 1 \mu \mathrm{m}$. On the other hand, the beam size slightly decreases and makes a waist at the anode entrance due to the electrostatic focusing provided by the hollow cathode geometry. With an accelerating field of $50 \mathrm{MV} / \mathrm{m}, 6 \mathrm{~mm}$ gap and $200 \mathrm{pC}$ bunch charge, the nonlinear space charge effects, and also the nonlinear radial defocusing field of anode iris [11], are responsible for the rapid increase of emittance. The emittance reaches $\sim 1.2 \mu \mathrm{m}$ at the exit of the anode $(z=$ $20 \mathrm{~mm}$ ). To preserve this emittance value, it is important to adjust the pulsed solenoid and realize the beam emittance compensation [21] at the rf cavity entrance plane. Pulsed solenoid focusing of the beam is illustrated on Fig. 5 (bottom) with beam size reduction for $z>60 \mathrm{~mm}$. If the matching is properly done, the acceleration in the $\mathrm{rf}$ cavity will decrease the projected emittance $(0.5 \mathrm{~m}<z<$ $0.8 \mathrm{~m}$ ). The two double solenoids in the diagnostic line are then used to minimize the bunch projected emittance at the location of the measurements. The location of the pinhole array used for emittance measurements is at $z=2.1 \mathrm{~m}$ which is for these simulation conditions not the position of a minimum emittance. Indeed, for the conditions of Fig. 5 the projected emittance is about $2 \mu \mathrm{m}$ at $z=2.1 \mathrm{~m}$.

\section{ELECTRON BEAM EXPERIMENTAL CHARACTERIZATION}

\section{A. Emittance measurements}

Although the increase of emittance in the diode part is important because of nonlinear space charge and anode iris effects, it is partially compensated by the nonlinear electrostatic focusing of the hollow cathode geometry [31,32]. Figure 6 shows a comparison for two different cathode geometries: with (hollow cathode) and without electrostatic focusing (elliptical shape). The machine parameters have been optimized for the highest charge and were kept constant while decreasing the charge. Charge is varied by attenuation of laser intensity and/or reduction of laser spot diameter. The effect of electrostatic focusing on projected emittance is important and simulations reproduce well the experimental results. The electrostatic focusing produces a beam waist at the anode iris entrance with a local emittance minimum in the gap (see also Fig. 5). The emittance minimum obtained in the gap is almost recovered after crossing the anode. In the case of the elliptical electrode, the compensation of space charge and anode iris defocusing forces does not happen; the beam is then larger and diverges when entering the anode iris. In consequence, the outer radial part of the bunch passes at very small distance from the inner surface of the anode iris where fields are highly nonlinear [11]. This leads to a stronger emittance growth when crossing the anode iris in comparison to the hollow electrode.

For charge below $20 \mathrm{pC}$, space charge effects in the diode are less important and quite small values of

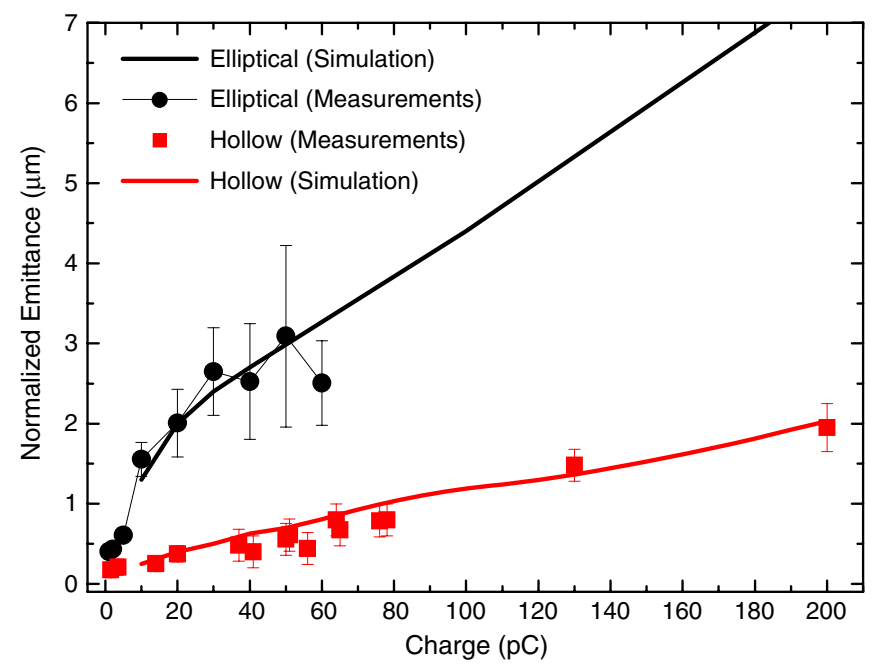

FIG. 6. Projected normalized emittance versus charge for two cathode shapes: elliptical (copper) and hollow (copper insert); $\quad \gamma \mathrm{mc}^{2}=5.11 \mathrm{MeV} ; \quad V_{\text {pulser }}=300 \mathrm{kV} ; \quad g=6 \mathrm{~mm}$; $\sigma_{t, \text { laser }}=4.2$ ps Gaussian time profile. From 0 to $80 \mathrm{pC}: D_{\text {laser }}=$ $0.9 \mathrm{~mm}$ and laser energy is varied; for $130 \mathrm{pC}: D_{\text {laser }}=1.4 \mathrm{~mm}$; for $200 \mathrm{pC}$ : $D_{\text {laser }}=1.8 \mathrm{~mm}$.

emittance can be reached. Figure 7 shows the typical beam shape produced by the diode/rf gun with the DLC hollow cathode and a copper insert at a charge of $13 \mathrm{pC}$. The right part of the figure shows the corresponding pepper-pot image obtained in the emittance monitor. From the image, an rms normalized projected emittance of $\varepsilon_{n, x}=0.23 \pm 0.05 \mu \mathrm{m}$ was determined. Such beam quality fulfills the emittance requirements for the low charge operation mode of the SwissFEL project (10 pC;

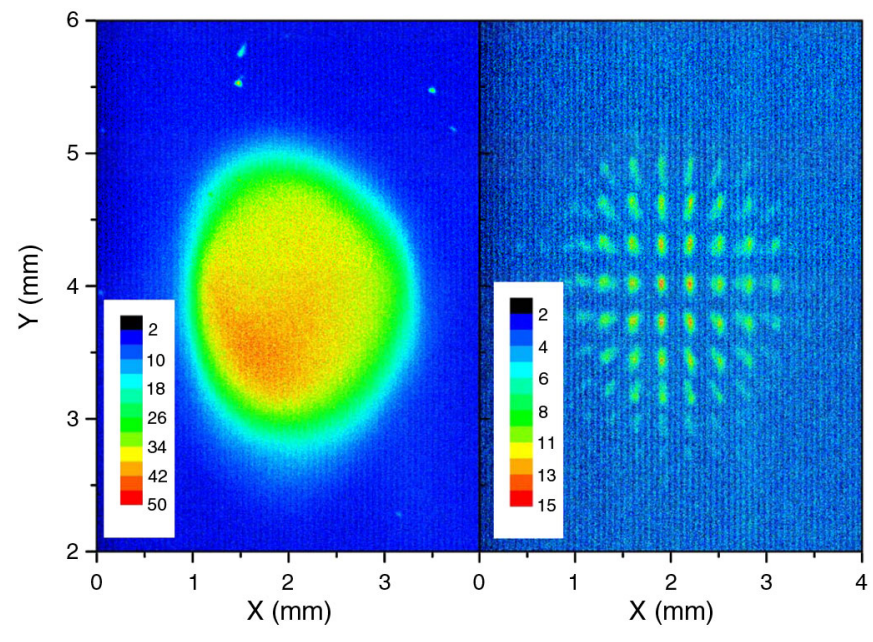

FIG. 7. Electron beam on a YAG screen in the emittance monitor (left) and when a pepper-pot mask is inserted $400 \mathrm{~mm}$ upstream (right) $\left(\gamma \mathrm{mc}^{2}=5.61 \mathrm{MeV} ; Q=13 \mathrm{pC} ; D_{\text {laser }}=\right.$ $0.5 \mathrm{~mm} ; \quad \varepsilon_{n X}=0.23 \mu \mathrm{m} ; \quad V_{\text {pulser }}=300 \mathrm{kV} ; \quad g=6 \mathrm{~mm}$; $\sigma_{t, \text { laser }}=4.2$ ps Gaussian time profile; copper). 
TABLE II. Summary table of the best measured emittance obtained with the diode-rf gun for the two modes of operation of SwissFEL (10 and 200 pC). Emittance at 200 pC corresponds to an average over more than ten measurements.

\begin{tabular}{lcccc}
\hline \hline Parameter & Symbol & Mode $10 \mathrm{pC}$ & Mode 200 $\mathrm{pC}$ & Unit \\
\hline Charge & $Q$ & 10 & 200 & $\mathrm{pC}$ \\
Final gun energy & $\gamma \mathrm{mc}^{2}$ & 5.61 & $5.76-6.5$ & $\mathrm{MeV}$ \\
Laser pulse length (rms) & $\sigma_{t, \text { laser }}$ & 4.2 & 2.6 & $\mathrm{ps}$ \\
Laser spot diameter on cathode & $D_{\text {laser }}$ & 0.5 & $0.9-1.4$ & $\mathrm{~mm}$ \\
Laser wavelength & $\lambda$ & 262 & 274 & $\mathrm{~nm}$ \\
Cathode material & & $\mathrm{Cu}$ & $\mathrm{Nb} ; \mathrm{Al}$ & \\
Diode peak field & $F_{\max }$ & 50 & $66-100$ & $\mathrm{MV} / \mathrm{m}$ \\
Cathode surface gradient & $F_{\text {eff }}$ & 25 & $33-50$ & $\mathrm{MV} / \mathrm{m}$ \\
Diode gap & $\mathrm{Gap}$ & 6 & $5-7$ & $\mathrm{~mm}$ \\
Diode voltage & $V_{\text {pulser }}$ & 300 & $330-500$ & $\mathrm{kV}$ \\
Projected emittance & $\varepsilon_{n, x}$ & $0.23 \pm 0.05$ & $1.25 \pm 0.2$ & $\mu \mathrm{m}$ \\
\hline \hline
\end{tabular}

$0.25 \mathrm{~mm} \mathrm{mrad})$. This emittance is also comparable to what is obtained in state of the art rf-photoguns [13,33].

Table II summarizes the best obtained normalized projected emittance in the diode-rf gun for the two modes of operation of SwissFEL: $10 \mathrm{pC}$ and $200 \mathrm{pC}$. The best obtained emittance of $1.25 \pm 0.2 \mu \mathrm{m}$ at $200 \mathrm{pC}$ corresponds to a statistical average over more than ten measurements done for slightly different experimental conditions: diode peak gradient between 66 and $100 \mathrm{MV} / \mathrm{m}$; different solenoid settings; $\mathrm{Nb}$ and $\mathrm{Al}$ inserts. Some of these measurements are discussed in Sec. IV C.

\section{B. Momentum and momentum spread characterization}

The spectrometer arm is used to measure the mean momentum and momentum spread of the electron beam as a function of the rf phase. In contrast to an rf photogun, the electron beam enters the rf cavity with nonzero energy (the pulser energy). Figure 8 represents a typical rf phase scan used to measure the beam momentum and to adjust the phase in order to minimize the bunch momentum spread. Indeed, the minimum emittance is obtained when the rf phase is adjusted for minimum electron energy spread. Two different laser pulse durations of $\sigma_{t, \text { laser }}=$ $0.6 \mathrm{ps}(\mathrm{rms})$ and $\sigma_{t, \text { laser }}=0.1 \mathrm{ps}(\mathrm{rms})$ are presented in Fig. 8. The rf electromagnetic wave in the cavity is a standing wave and the phase $\varphi_{\mathrm{rf}}$ is defined such that $\varphi_{\mathrm{rf}}=$ 0 is for the maximum measured mean momentum. The minimum uncorrelated energy spread is about $8 \mathrm{keV}(\mathrm{rms})$ for $\sigma_{t, \text { laser }}=0.6 \mathrm{ps}(\mathrm{rms})$ and about $4 \mathrm{keV}$ for $\sigma_{t, \text { laser }}=$ $0.1 \mathrm{ps}$ (rms). This minimum is shifted to $\varphi_{\mathrm{rf}} \sim 10$ degrees for $\sigma_{t, \text { laser }}=0.6 \mathrm{ps}$ and to $\varphi_{\mathrm{rf}} \sim 15$ degrees for $\sigma_{t, \text { laser }}=$ $0.1 \mathrm{ps}$ because of longitudinal space charge effects. The typical stability of the $\mathrm{rf}$ phase is around $1^{\circ}$ (peak to peak) leading to energy fluctuations between bunches of $20 \mathrm{keV}$ (peak to peak). Such large fluctuations are due to the modulator stability and to the fact that the klystron is running at only $20 \%$ of its maximum power (20 MW).

\section{Comparisons between simulation and experiment}

As shown previously in Fig. 6, there is good agreement between ASTRA predictions and measurements for the projected emittance. Simulations of the beam dynamics in the case of elliptical electrodes were also performed with the code OPAL [34] and compared to measurements. Figure 9 shows a comparison between the measured and calculated

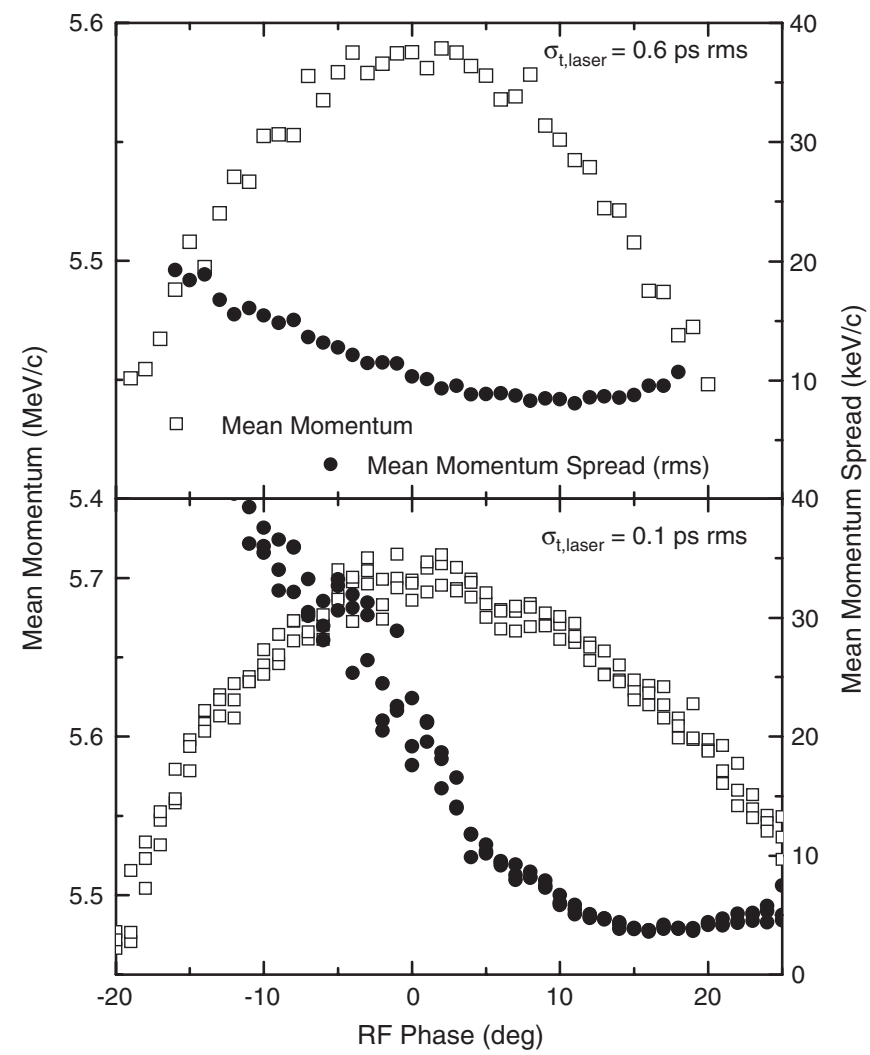

FIG. 8. Momentum and momentum spread versus the rf phase $\varphi_{\text {rf }}$ for a laser pulse duration of $\sigma_{t, \text { laser }}=0.6 \mathrm{ps} \mathrm{rms} \mathrm{(top)} \mathrm{and}$ $\sigma_{t, \text { laser }}=0.1 \mathrm{ps} \quad$ (bottom); $Q=10 \mathrm{pC} ; \quad D_{\text {laser }}=0.5 \mathrm{~mm}$; $V_{\text {pulser }}=300 \mathrm{kV}$; gap $=6 \mathrm{~mm}$; copper insert. 


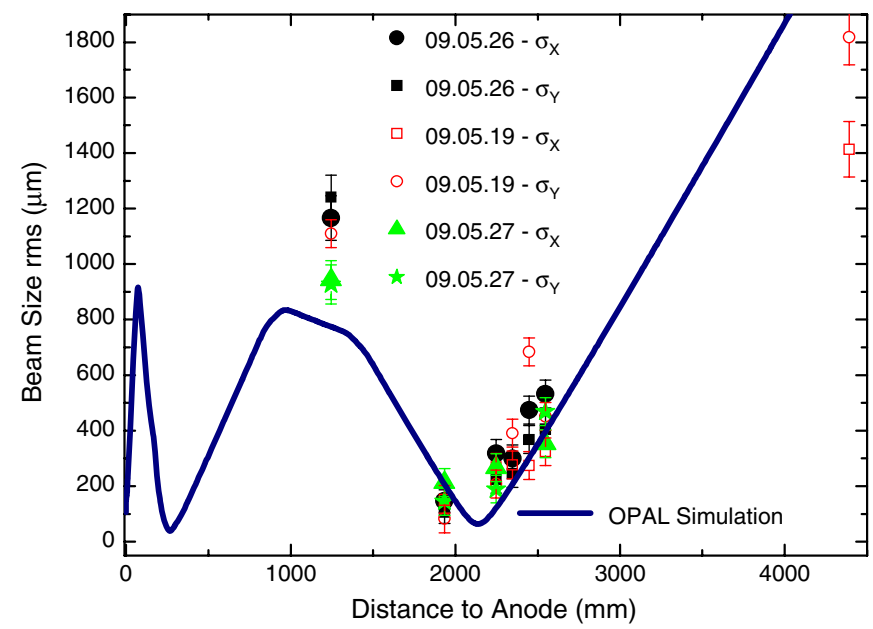

FIG. 9. Simulations of the transverse electron beam size (rms) along the machine axis compared to measurements on different days. $\quad\left(\gamma \mathrm{mc}^{2}=4.911 \mathrm{MeV} ; \quad Q=10 \mathrm{pC} ; \quad D_{\text {laser }}=0.9 \mathrm{~mm}\right.$; $V_{\text {pulser }}=300 \mathrm{kV} ; \quad$ gap $=6 \mathrm{~mm} ; \quad \varphi_{\mathrm{rf}}=15 \mathrm{deg} ; \quad B_{\mathrm{PSL}}=$ $130 \mathrm{mT} ; B_{\mathrm{DSL} 1}=116 \mathrm{mT} ; B_{\mathrm{DSL} 2}=87 \mathrm{mT}$ ).

beam size along the machine axis. The first measurement screen is at $z \sim 1.2 \mathrm{~m}$, just after the in-coupling laser mirror. Several measurements with the same machine parameters, but acquired on different days, are shown and give an idea of the beam reproducibility (typically $25 \%$ peak to peak variation in beam size after one day). The agreement with simulation is rather good, given that simulations assume an ideal flat top profile for the transverse laser intensity distribution. In reality, variations as large as $50 \%$ peak to peak [27] are present in the laser transverse intensity distribution.

OPAL is a 3D PIC code [34] which provides the beam transverse profile via projection on a virtual screen (see Fig. 10). The formation of a toroidal beam shape as observed in the gun test stand is qualitatively reproduced in simulation. The hollow shape shown in Fig. 10 results from

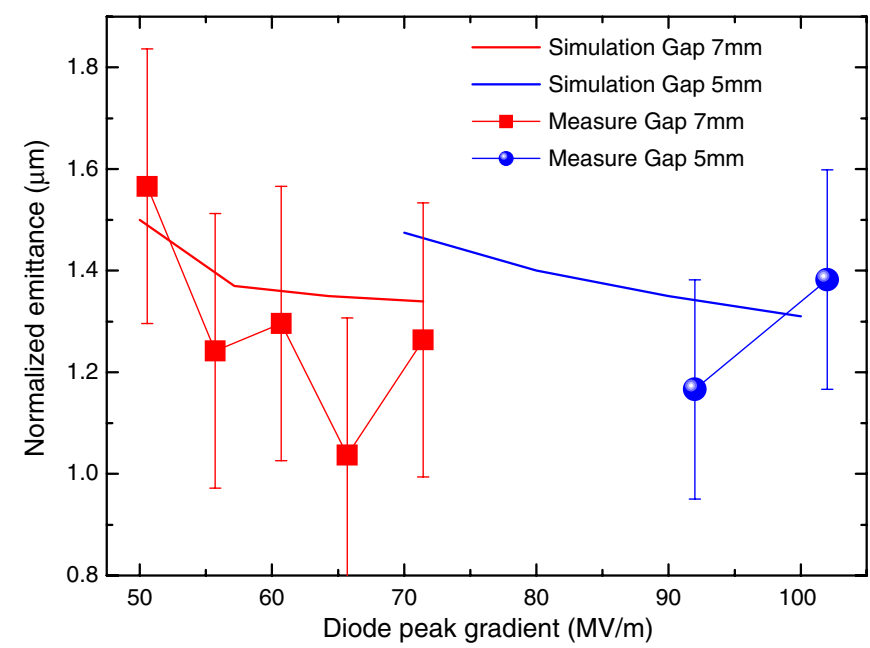

FIG. 11. Normalized projected emittance versus diode peak gradient for different anode-cathode gaps. Measured data (dots) are compared to simulations (lines). $\left(\gamma \mathrm{mc}^{2}=5.51 \mathrm{MeV} g=5\right.$ to $7 \mathrm{~mm} ; 200 \mathrm{pC} ; \sigma_{t \text {, laser }}=3 \mathrm{ps}$, Gaussian time profile; $D_{\text {laser }}=$ $1.4 \mathrm{~mm}$; DLC hollow cathode with a niobium insert).

the counteracting magnetic focusing forces (linear to the first order with the radial position) and the radial repulsive space charge forces (highly nonlinear with the radial position) as sometimes observed in other electron guns [35,36].

The nominal beam $(200 \mathrm{pC} ; 0.4 \mu \mathrm{m})$ required for high charge operation at SwissFEL is not reached with the conditions of Fig. 6. Indeed, for the hollow cathode geometry and $V_{\text {pulser }}=300 \mathrm{kV}, g=6 \mathrm{~mm}$, the rms projected emittance is $1.9 \mathrm{~mm}$ mrad \pm-0.2 for a charge of $200 \mathrm{pC}$ and $5.5 \mathrm{MeV}$ beam momentum (see Fig. 6). Best emittance values were obtained with the Ti:sapphire laser system and a shorter pulse duration of $\sigma_{t \text {,laser }}=3 \mathrm{ps}$ (Gaussian longitudinal profile) as shown in Figs. 11 and 12 for a $200 \mathrm{pC}$ beam. The wide error bars correspond to the difference in emittance when taking into account $100 \%$ or $90 \%$ of the charges (see Sec. IV D). The minimum
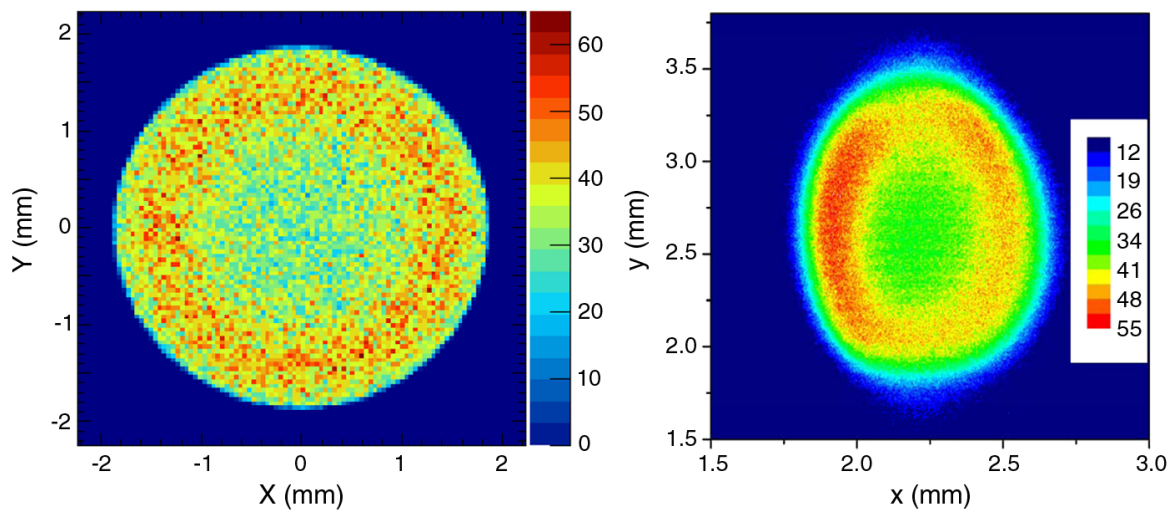

FIG. 10. Transverse beam profile simulated with OPAL (left) and measured on a fluorescent screen (right); $14 \mathrm{pC} ; 5.5 \mathrm{MeV} ; z=$ $2.6 \mathrm{~m} ; V_{\text {pulser }}=300 \mathrm{kV} ;$ gap $=6 \mathrm{~mm} ; \varphi_{\mathrm{rf}}=15 \mathrm{deg} ; B_{\mathrm{PSL}}=135 \mathrm{mT} ; B_{\mathrm{DSL} 1}=92 \mathrm{mT}(125 \mathrm{mT}$ in simulation $) ; B_{\mathrm{DSL} 2}=81 \mathrm{mT}$ (100 $\mathrm{mT}$ in simulation). 
projected emittance (at $90 \%$ charge) ranges between 1.0 and $1.6 \mu \mathrm{m}$ for a peak diode gradient going from 50 to $100 \mathrm{MV} / \mathrm{m}$ (see Fig. 11). This rather small dependence on gradient is also confirmed by simulation. Considering the error bars on Fig. 11, an average of the best projected emittance obtained with this diode-rf gun is $1.25 \pm$ $0.2 \mu \mathrm{m}$ (Table II). Figure 12 represents the typical transverse beam profile for the nominal charge of $200 \mathrm{pC}$ and the corresponding pepper-pot image. The beam asymmetry is due to the laser transverse profile.

This emittance is above the maximum allowed value for the SwissFEL operation. However, the longitudinal laser profile in the case of Figs. 11 and 12 was Gaussian and simulations (Fig. 13) show that, with a flattop laser time profile [11.3 ps full width (FW) and $0.7 \mathrm{ps}$ rise and fall time] the projected emittance can be decreased by as much as $30 \%$. Indeed, Fig. 13 (left) represents the simulated projected emittance (ASTRA) at the exit of the diode for a uniform longitudinal laser profile. For a gap of $5 \mathrm{~mm}$ and a voltage of $500 \mathrm{kV}$, the predicted emittance is $0.8 \mu \mathrm{m}$ as it was $1.4 \pm 0.2 \mu \mathrm{m}$ in the measurements $(1.35 \mu \mathrm{m}$ in the simulation) with the Gaussian laser profile of Fig. 11.

The simulation results of Fig. 13 also show that an increase of the diode gradient to $150 \mathrm{MV} / \mathrm{m}(600 \mathrm{kV}$; $4 \mathrm{~mm}$ gap) together with a reduction of $C_{\text {radius }}$ to $2 \mathrm{~mm}$ $\left[C_{\text {radius }}\right.$ is the hollow cathode opening as defined in Fig. 2 (right)] would bring the projected emittance down to around $0.4 \mu \mathrm{m}$. The good agreement between ASTRA simulations and measurements obtained in Figs. 6 and 11 as well as agreement with OPAL simulations in Figs. 9 and 10 give reason to be confident on this emittance expectation.
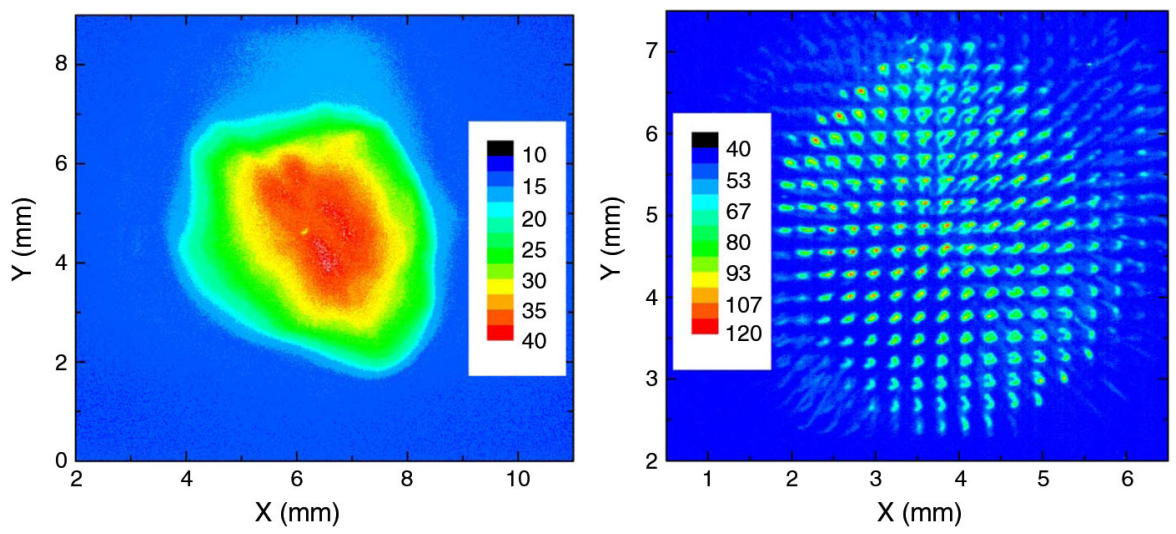

FIG. 12. Beam transverse profile at $z=1.9 \mathrm{~m}$ (left); pepper-pot image at $z=2.42 \mathrm{~m} ; \varepsilon_{n, x}=1.25+/-0.2 \mu \mathrm{m}$ (right); $\gamma \mathrm{mc}{ }^{2}=$ $5.49 \mathrm{MeV} ; 200 \mathrm{pC} ; V_{\text {pulser }}=350 \mathrm{kV} ; g=7 \mathrm{~mm}$; Nb (110) insert; $\sigma_{t, \text { laser }}=3 \mathrm{ps}$, Gaussian time profile; $D_{\text {laser }}=1.8 \mathrm{~mm}$.
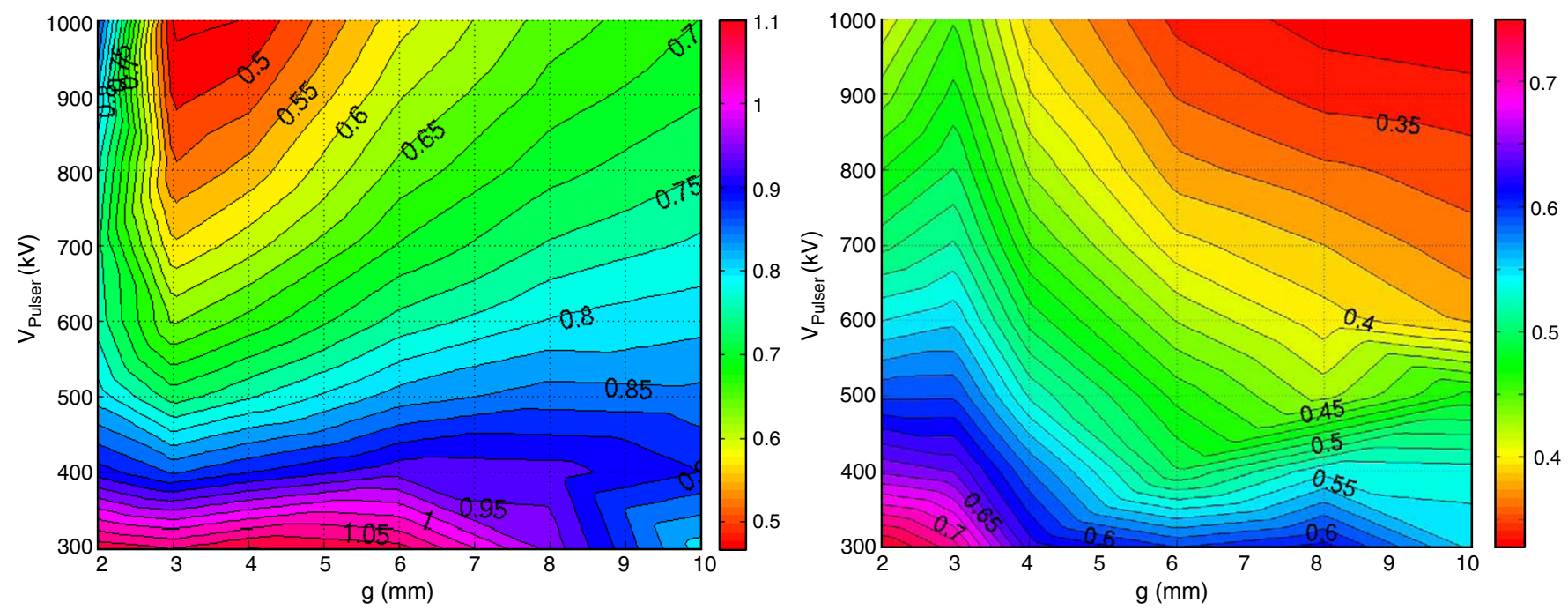

FIG. 13. Simulated map of the normalized projected emittance (in $\mu \mathrm{m}$ ) at the exit of the anode $(z=20 \mathrm{~mm})$ with a hollow cathode opening $\left(C_{\text {radius }}\right.$ ) of radius $3 \mathrm{~mm}$ (left) and $2 \mathrm{~mm}$ (right). $g$ corresponds to the diode gap in mm and $V_{\text {pulser }}$ is the voltage applied across the diode. ASTRA simulation conditions: $200 \mathrm{pC}$; uniform laser profile $D_{\text {laser }}=1.08 \mathrm{~mm}$; rise $/$ fall time $=0.7 \mathrm{ps}$; $11.3 \mathrm{ps}$ full width. 


\section{Intrinsic emittance}

The intrinsic emittance is the ultimate lower limit in beam emittance that can be reached for a given cathode material, surface electric field, and laser wavelength. The intrinsic emittance can be expressed as [37]

$$
\varepsilon_{\text {intrinsic }}=\sigma_{x} \sqrt{\frac{h \nu-\Phi_{0}+e^{3 / 2} \frac{F_{\text {eff }}^{1 / 2}}{\left(4 \pi \varepsilon_{0}\right)^{1 / 2}}}{3 \mathrm{mc}^{2}}},
$$

where $\sigma_{x}$ is the rms horizontal beam size in $m, h v$ the laser photon energy in $J, \Phi_{0}$ the work function of the material in $J, e$ the elementary charge, $F_{\text {eff }}$ the electric field on cathode surface in $V / m$, and $\varepsilon_{0}$ the vacuum permittivity. Measurements of projected emittance at very low charge below $1 \mathrm{pC}$ (where space charge effects can be neglected) and short pulse duration should approach this limit of intrinsic emittance. Figure 14 illustrates such measurements for two different photocathode insert materials: polycrystalline $\mathrm{Cu}$ and single crystal $\mathrm{Nb}$. The agreement between the two measurement methods (pepper pot and solenoid scan) is rather good. During a solenoid scan, the electron beam size downstream of the solenoid is recorded as a function of the solenoid current. The transfer matrix of the solenoid has been calculated with the measured solenoid field map. The best fit to the measurement (beam size versus solenoid current) using the transfer matrix coefficient gives then the emittance value [15].

The theoretical slopes are very close to the data points in Fig. 14 if one assumes a work function of $4.13 \mathrm{eV}$ for niobium $\mathrm{Nb}$ and $4.3 \mathrm{eV}$ for $\mathrm{Cu}$. These values are compatible with the literature $\left(\Phi_{\mathrm{Nb}}=4.37 \mathrm{eV}\right.$ [38] and $\Phi_{\mathrm{Cu}}=$ $4.31 \mathrm{eV}$ [39]) if one takes into account surface contamination of our sample (up to $1 \mathrm{eV}$ variation can come with oxidation contamination [38]) or roughness effects which

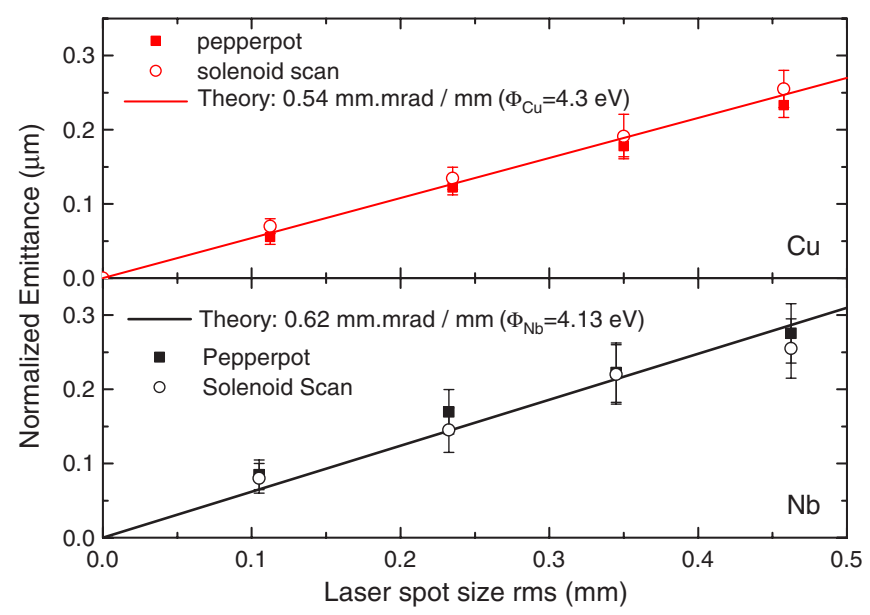

FIG. 14. Normalized projected emittance versus laser spot size (rms) for $\mathrm{Cu}$ cathode insert (top) and a (110) $\mathrm{Nb}$ cathode insert (bottom) $\quad\left(Q<1 \mathrm{pC} ; \quad 274 \mathrm{~nm} ; \quad \sigma_{t, \text { laser }}=3 \mathrm{ps} ; \quad \gamma \mathrm{mc}^{2}=\right.$ $5.51 \mathrm{MeV})$. can change the effective work function of our samples [40,41]. Including the Schottky effect, due to the applied electric field $(25 \mathrm{MV} / \mathrm{m})$, the barrier is reduced to $3.93 \mathrm{eV}$ for $\mathrm{Nb}$ and 4.1 for $\mathrm{Cu}$. The initial kinetic energy of the electrons is then about $0.6 \mathrm{eV}$ for $\mathrm{Nb}$ and $0.43 \mathrm{eV}$ for $\mathrm{Cu}$ when using $274 \mathrm{~nm}$ photons $(4.53 \mathrm{eV})$. Similar measurements were performed on other materials $(\mathrm{Al}, \mathrm{Mo}, \ldots)$ and the laser wavelength was then varied to minimize the initial electron kinetic energy. These results are discussed in [15]. If the initial electron kinetic energy varies with the surface gradient, there is also an effect on the quantum efficiency. Indeed the quantum efficiency $(\mathrm{QE})$ increases with gradient due to the Schottky effect [37,42]. The QE dependence on surface gradient could give an estimation of the cathode work function by comparison with a photon limited emission theory such as described in [37]. In the case of Fig. 15, the emitted charge is clearly space charge limited and no information on cathode work function can therefore be deduced. Space charge limited emission, assuming a transversely uniform laser, can be approximated with the following expression:

$$
Q_{\mathrm{SCL}}=\varepsilon_{0} \pi\left(\frac{D_{\text {laser }}}{2}\right)^{2} F_{\text {eff }}
$$

with $F_{\text {eff }}$ being the electrical gradient on cathode insert. Assuming a laser spot size of $D_{\text {laser }}=1.08 \mathrm{~mm}$, the simple space charge consideration [Eq. (15)] fits well to the measured data of Fig. 15. This laser spot size is comparable to the experimental laser spot size of $D_{\text {laser }}=1.8 \mathrm{~mm}$, taking into account the large nonuniformities in the laser transverse distribution of $\sim 50 \%$.

Some charges might also be lost on the anode iris. Nevertheless, Fig. 15 clearly illustrates the rapid increase of charge with surface gradient, $100 \mathrm{pC}$ charge increase with only $15 \mathrm{MV} / \mathrm{m}$ surface field increase. This is a way to

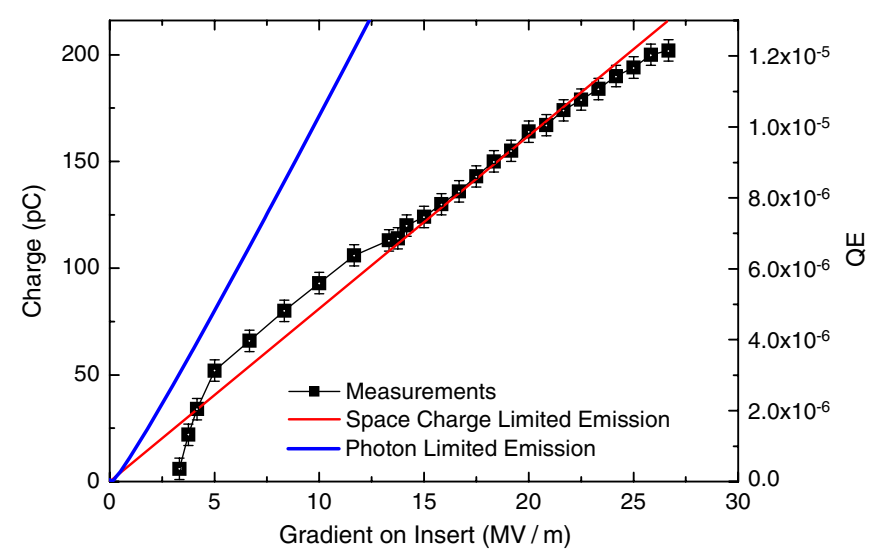

FIG. 15. Charge versus gradient on a copper insert $(\lambda=$ $262 \mathrm{~nm}, \quad E_{262 \mathrm{~nm}}=79 \mu \mathrm{J} ; \quad \gamma \mathrm{mc}^{2}=5.76 \mathrm{MeV} ; \quad \sigma_{t, \text { laser }}=$ $\left.4.2 \mathrm{ps} ; D_{\text {laser }}=1.8 \mathrm{~mm} ; g=6 \mathrm{~mm}\right)$. Space charge limited emission [Eq. (15)] assuming $D_{\text {laser }}=1.08 \mathrm{~mm}$ (see text); photon limited emission theory corresponds to Eq. (10) of Ref. [37] assuming $\Phi_{\mathrm{Cu}}=4.75 \mathrm{eV}$. 
economize laser energy which could be invested in an improved laser profile. Indeed a large fraction of laser energy is lost in the mask aperture used to get a uniform transverse laser intensity profile. High quantum efficiency is an indirect way of improving the laser transverse profile.

\section{SUMMARY}

We have characterized the electron beam coming from a diode/rf gun assembly by measuring the projected emittance, the beam size evolution, the momentum and momentum spread for various conditions of charge and diode gradient and/or diode voltage. Good agreement between simulation and measurement was obtained. This allowed us to understand the effect of the cathode geometry on transverse electrostatic focusing as well as space charge induced features such as the toroidal beam. Particular care was taken for the emittance diagnostics [quality of pepperpot images and analysis tool (XANAROOT)]. Stable operation with diode peak electric fields of $100 \mathrm{MV} / \mathrm{m}$ for periods of several days could be demonstrated with the DLC coating on both electrodes. The chosen hollow cathode geometry gives encouraging projected normalized emittance values as low as $0.23 \mu \mathrm{m}$ with $13 \mathrm{pC}$. Projected emittance at charges below $1 \mathrm{pC}$ was measured with two different techniques (pepper pot and solenoid scan) and agrees well with thermal emittance theory. Systematic study of the thermal emittance for different cathode material, surface finishing, and/or laser wavelength is now possible. For the nominal beam charge of $200 \mathrm{pC}$ required for SwissFEL, the smallest projected normalized emittance obtained was $1.25 \pm 0.2 \mu \mathrm{m}$, which is larger than the requirement. However, simulation predicts that a flattop laser time profile together with small modifications of the cathode geometry (electrostatic focusing) should enable us to reach a projected emittance as low as $0.4 \mu \mathrm{m}$.

\section{ACKNOWLEDGMENTS}

The authors would like to thank S. Tsujino (LMN-PSI) for providing the Mo coated electrodes. We also thank AM. Valente-Feliciano from JLAB for providing the single crystal $\mathrm{Nb}$ cathode insert samples. The authors also acknowledge the support of PSI-OBLA team.

[1] SwissFEL, http://www.psi.ch/swissfel/.

[2] B. D. Patterson, Paul Scherrer Institut Report No. 09-10, 2009.

[3] B. D. Patterson et al., New J. Phys. 12, 035012 (2010).

[4] R. J. Bakker et al., Proceedings of the FEL06 Conference, Ultra High Brightness Accelerator Design, Berlin, Germany, 2006.

[5] E. Kirk et al., J. Vac. Sci. Technol. B 27, 1813 (2009).

[6] M. Paraliev et al., Proceedings of the IEEE International Power Modulator \& High Voltage Conference
Conference, Experimental Study of Diamond Like Carbon (DLC) Coated Electrodes for Pulsed High Gradient Electron Gun, Atlanta, GA, 2010 (arXiv:1006.2001).

[7] F. B. Kiewiet et al., Proceedings of the EPAC 2002 Conference, A DC/RF Gun For Generating Ultra-Short High Brightness Electron Bunches, Paris, France, 2000.

[8] D. Yu et al., in Proceedings of the 20th Particle Accelerator Conference, Portland, OR, 2003 (IEEE, New York, 2003), pp. 2132-2134.

[9] M. J.d. Loos et al., in Proceedings of the 8th European Particle Accelerator Conference, Paris, 2002 (EPS-IGA and CERN, Geneva, 2002), p. 1831.

[10] T. Srinivasan-Rao et al., in Proceedings of the 18th Particle Accelerator Conference, New York, 1999 (IEEE, New York, 1999), p. 75.

[11] S. B. v. d. Geer et al., Phys. Rev. E 65, 046501 (2002).

[12] J. Smedley et al., in Proceedings of the 20th Particle Accelerator Conference, Portland, OR, 2003 (Ref. [8]), p. 541 .

[13] F. Stephan et al., Phys. Rev. ST Accel. Beams 13, 020704 (2010).

[14] R. Akre et al., Phys. Rev. ST Accel. Beams 11, 030703 (2008).

[15] C. Hauri et al., Phys. Rev. Lett. 104, 234802 (2010).

[16] G. A. Mesyats and D. I. Proskurovsky, Pulsed Electrical Discharge in Vacuum (Springer-Verlag, Berlin, 1989).

[17] F. L. Pimpec et al., arXiv:1003.3594 [J. Vac. Sci. Technol. A (to be published)].

[18] F. L. Pimpec et al., Nucl. Instrum. Methods Phys. Res., Sect. A 574, 7 (2007).

[19] http://www.bekaert.com/.

[20] LANL, Poisson, http://laacg.lanl.gov/laacg/services/.

[21] C.-X. Wang et al., Phys. Rev. ST Accel. Beams 10, 104201 (2007).

[22] M. Paraliev, Paul Scherrer Institut Report No. FEL-PA84005-0, 2008.

[23] K. Li, Ph.D. thesis, ETH Zurich, 2008.

[24] K. T. McDonald and D. P. Russel, in Proceedings of the Joint U.S.-CERN Accelerator School on Observation, Diagnostics and Correction in Particle Beams Conference, Methods of Emittance Measurement, Capri, Italy, 1988.

[25] V. Schlott et al., in Proceedings of the DIPAC Conference, Design and Calibration of an Emittance Monitor for the PSI XFEL Project, Venice, Italy, 2007, p. 198.

[26] A. Streun, Paul Scherrer Institut Report No. FEL-SA84001-1, 2007.

[27] C. Hauri et al., in Proceedings of the FEL09 Conference, Gun Laser System for the Low Emittance SwissFEL, Liverpool, UK, 2009, p. 197.

[28] S. J. Anderson et al., Phys. Rev. ST Accel. Beams 5 014201 (2002).

[29] T. Schietinger, PSI, http://amas.web.psi.ch/tools/ XanaROOT/.

[30] K. Floettmann, DESY, http://www.desy.de/ mpyflo/.

[31] R. Ganter et al., in Proceedings of the FEL09 Conference, Commissioning of a Diode/RF Photogun Combination, Liverpool, UK, 2009.

[32] K. Li, Paul Scherrer Institut Report No. FEL-LK06-00401, 2009. 
[33] Y. Ding et al., Phys. Rev. Lett. 102, 254801 (2009).

[34] A. Adelmann et al., in Proceedings of the 23rd Particle Accelerator Conference, Vancouver, Canada, 2009 (IEEE, Piscataway, NJ, 2009).

[35] M. Reiser, Theory and Design of Charged Particle Beams, edited by M. Month (John Wiley \& Sons, New York, 1994).

[36] M. Krasilnikov et al., in in Proceedings of the 23rd Particle Accelerator Conference, Vancouver, Canada, 2009 (Ref. [34]).
[37] D. H. Dowell and J.F. Schmerge, Phys. Rev. ST Accel. Beams 12, 074201 (2009).

[38] B. J. Hopkins and M. Ibrahim, Vacuum 23, 135 (1973).

[39] D. H. Dowell et al., Phys. Rev. ST Accel. Beams 9, 063502 (2006).

[40] W. Li and D. Y. Li, J. Chem. Phys. 122, 064708 (2005).

[41] K.L. Jensen et al., Appl. Phys. Lett. 88, 164105 (2006).

[42] K. L. Jensen et al., J. Appl. Phys. 102, 074902 (2007). 